\title{
Rapid timing of a single transition in interfood interval duration by rats
}

\author{
JENNIFER J. HIGA \\ Duke University, Durham, North Carolina
}

\begin{abstract}
The present experiment examined temporal control of wait-time responses by interfood interval (IFI) duration. We exposed rats to a sequence of intervals that changed in duration at an unpredictable point within a session. In Phase 1, intervals changed from 15 to $5 \mathrm{sec}$ (step-down) or from 15 to $45 \mathrm{sec}$ (step-up). In Phase 2, we increased the intervals by a factor of four. We observed rapid timing effects during a transition in both phases of the experiment: A step-down and a step-up transition significantly decreased and increased wait time in the next interval, respectively. Furthermore, adjustment of wait times during step-down was largely complete by the third transition IFI. In contrast, wait times gradually increased across several transition IFIs during step-up. The results reveal dynamic properties of temporal control that depend on the direction in which IFIs change.
\end{abstract}

Organization of behavior by the time between food presentations has been demonstrated in a variety of animals ranging from rats and pigeons (see, e.g., Richelle \& Lejeune, 1980) to captive starlings (e.g., Brunner, Kacelnik, \& Gibbon, 1992) to fish and turtles (Lejeune \& Wearden, 1991). For example, animals given extended exposure to fixed-interval (FI) reinforcement schedules come under the control of the time between reinforcer deliveries (interfood interval, IFI). A hallmark of responding during FI schedules is a postreinforcement wait time that is proportional to the IFI duration (Lowe \& Harzem, 1977; Shull, 1970; Zeiler \& Powell, 1994).

FI schedules and other timing procedures (e.g., the peak procedure; Catania, 1970; Roberts, 1981) are usually studied for the steady-state behavior they generate. Many quantitative properties have been discovered (e.g., scalar timing; Gibbon, 1977) that have been useful in testing and developing models of timing. Leading models in this area are scalar expectancy theory (SET; Church, 1984; Gibbon, 1977; Gibbon \& Church, 1984) and the behavioral theory of timing (BeT; Killeen \& Fetterman, 1988). Both are essentially molar models. SET's assumption about memory for time intervals, for example, is based on statistical distributions derived from molar features of a pacemaker system and reinforcement schedule (e.g., Gibbon, 1991, 1995; Gibbon \& Church, 1984). BeT, too, is based on molar properties. According to BeT, adjunctive responses mediate time discrimination, and these responses are assumed to be associated with transitions be-

The research was supported by a Duke University Arts and Sciences Research Grant to the author. Portions of this paper were presented at the Eighteenth Annual Conference of the Society for the Quantitative Analyses of Behavior, May 1995, Washington, D.C. The author thanks Erika Holz, Linda Liu, and Lynn Talton for help in running the experiments, and G. R. King for helpful comments on earlier drafts of the paper. Correspondence should be addressed to J. J. Higa, Department of Psychology: Experimental, Duke University, Box 90086, Durham, NC 27708-0086 (e-mail: jennifer@psych.duke.edu). tween states produced by pulses from a Poisson pacemaker. The pacemaker speed depends on the average time between reinforcers in a given context, as well as the amount and probability of reinforcement (e.g., Fetterman \& Killeen, 1991; Killeen \& Fetterman, 1988).

SET and BeT have made important contributions to the understanding of time discrimination. However, by focusing on molar properties of the experimental procedure or a theoretical process, the dynamics of timing have been largely unnoticed, and little is known about the acquisition process. The dynamics have been infrequently studied in the past perhaps in part because, with few exceptions (e.g., Gibbon \& Balsam, 1981), temporal control was assumed to be slow to develop. After all, under the usual conditions, steady-state performance requires many sessions and hundreds of trials of exposure to a single interval. For example, exposing animals to 30 or more sessions is not uncommon (e.g., Cheng \& Westwood, 1993; Innis, 1981; Meck \& Church, 1984; Schneider, 1969). In contrast, some studies (e.g., Wynne \& Staddon, 1988) show that temporal control develops rapidly, within a few trials. This recent discovery indicates that some part of the timing mechanism is fast-acting and provides an opportunity for studying its dynamics.

Experiments on rapid-timing effects involve brief exposure to an unsignaled transition in IFI duration during interval reinforcement schedules. A robust finding is the adjustment of wait time within one interval (e.g., Higa, Wynne, \& Staddon, 1991; Wynne \& Staddon, 1988). Under some conditions, wait time beyond the first IFI of a transition continues to change. For example, Higa, Thaw, and Staddon (1993) found that, during an unpredictable step-down decrease in IFI duration (from 15 to $5 \mathrm{sec}$ ), adjustment to the decrease was largely complete after a single IFI, as predicted by linear waiting. In comparison, an abrupt step-up transition (from 15 to $45 \mathrm{sec}$ ) caused wait time in the next IFI to increase according to a linear waiting process, but wait time continued to increase across sev- 
eral subsequent IFIs. In this case, wait time did not appear to depend solely on the preceding IFI duration. The immediate change in wait time followed by a gradual increase suggests that wait times during posttransition IFIs were affected by the shorter pretransition IFIs that occurred several IFIs ago.

The purpose of the present study was to obtain further empirical information about how adaptation of wait time depends on transitions in IFI duration and to test the generality of the temporal dynamics observed in prior rapidtiming studies with pigeons (e.g., Higa, Thaw, \& Staddon, 1993; Higa et al., 1991; Wynne \& Staddon, 1988, 1992; Wynne, Staddon, \& Delius, 1996). Specifically, we do not know whether those temporal dynamics also occur in rats. Although the generality of effects associated with interval reinforcement schedules is well supported (e.g., see Richelle \& Lejuene, 1980), it is still possible that the timing process may differ in rats and pigeons. For example, Lowe and Harzem (1977) argued that because pigeons are not able to space their responses in time on differential-reinforcement-of-low-rate (DRL) schedules with the same accuracy as rats (see Harzem, Lowe, \& Davey, 1975; Staddon, 1965), they may differ from rats in their ability to judge intervals of time. The present experiment examines this question by using Higa et al.'s (1993) step procedure to study temporal dynamics in rats.

Like Higa et al.'s (1993) procedure, rats were exposed to a series of IFIs that changed in duration once per session, either decreasing (step-down) or increasing (stepup). The location of a transition was random across sessions. Hence, although rats might have learned over the course of training that IFIs changed once per session, it is unlikely that changes in wait times were based on anticipating when a transition was about to occur. Unlike Higa et al.'s experiment, we studied the effects of transitions with two interval ranges. In one phase of the experiment, the intervals changed from 15 to $5 \mathrm{sec}$ or from 15 to $45 \mathrm{sec}$. In another phase, we increased the duration of all intervals by a factor of four and held constant the proportion by which intervals increased or decreased between phases. Furthermore, instead of a response-initiated delay (RID) schedule, we programmed the IFIs according to a standard FI reinforcement schedule.

\section{METHOD}

\section{Subjects}

Four adult male Sprague-Dawley rats (R5, R6, R7, and R8) served as subjects. All subjects had limited experience on standard fixed-ratio and FI reinforcement schedules. We studied the subjects 6 to 7 days a week and gave them supplementary food at the end of each day to maintain them at approximately $80 \%$ of their free-feeding body weight. The rats had free access to water in their home cage and were housed in a colony with a $14: 10$-h light:dark cycle. The experiment took place during the light part of the cycle.

\section{Apparatus}

We conducted the experiment in four standard operant chambers. Each chamber was approximately $27 \mathrm{~cm}$ wide, $31 \mathrm{~cm}$ deep, and $20 \mathrm{~cm}$ high. Mounted on the front panel of each chamber was
Table 1

Order of Conditions for Each Subject

\begin{tabular}{ccc}
\hline Subject & Phase 1 & Phase 2 \\
\hline R5 & SD, NS, SU, NS & NS, SU, NS, SD \\
R6 & SU, NS, SD, NS & NS, SD, NS, SU \\
R7 & NS, SD, NS, SU & NS, SU, NS, SD \\
R8 & NS, SU, NS, SD & NS, SD, NS, SU \\
\hline
\end{tabular}

Note-SD, step-down condition; NS, no-step condition; SU, step-up condition.

a flat lever, $5 \mathrm{~cm}$ long and $2 \mathrm{~cm}$ wide, $3.5 \mathrm{~cm}$ above the floor and $8 \mathrm{~cm}$ from the right wall to the center of the lever. Mounted directly above the lever was a lamp approximately $1.5 \mathrm{~cm}$ in diameter. We provided access to liquid reinforcers through an aperture $3 \mathrm{~cm}$ in diameter and $8 \mathrm{~cm}$ to the left of the lever, center to center. A houselight, located in the center of the ceiling, illuminated the chamber. A sound-attenuating apparatus enclosed each chamber, and a ventilation fan masked extraneous noise. An IBM-compatible computer (located in an adjacent room) and a compiled program written in BASIC controlled the experimental events and recorded all leverpresses by the subject.

\section{Procedure}

For all conditions, a session began with delivery of a reinforcer (marking the start of a session and the first IFI) followed by 50 IFIs programmed according to a standard FI schedule: A reinforcer was delivered for the first response that occurred after a fixed amount of time had elapsed since the preceding reinforcer delivery. The houselight was on throughout a session, and the light above the lever was always lit except during the delivery of the reinforcer. Reinforcement consisted of $3 \mathrm{sec}$ of access to a 0.10 -cc dipper holding $0.2 \mathrm{M}$ sugar-water solution to which almond extract was added ( $1.0 \mathrm{cc}$ per 2.01 of solution).

The experiment consisted of two phases. In Phase 1, we exposed the subjects to three conditions: no-step (baseline), step-down, and step-up. For the no-step condition, we programmed all IFIs to be $15 \mathrm{sec}$ in duration. The IFIs changed from 15 to $5 \mathrm{sec}$ during the step-down condition and from 15 to $45 \mathrm{sec}$ in the step-up condition. The conditions of Phase 2 were identical to those of Phase 1 , but we increased the duration of the IFIs by a factor of four. Thus, for the no-step condition, all IFIs were $60 \mathrm{sec}$ in duration. The IFIs changed from 60 to $20 \mathrm{sec}$ and from 60 to $180 \mathrm{sec}$ in the step-down and step-up conditions, respectively. The order of conditions (presented in Table 1) varied across subjects, and each condition was in effect for 14 sessions.

In the step-down and step-up conditions, the point of transition in IFI duration varied across sessions with two constraints: (1) a transition occurred after at least 10 IFIs had elapsed, and (2) each session contained at least 10 poststep IFIs. Hence, a transition could occur any time between the 10th and 41 st IFI. To illustrate these constraints, Figure 1 presents hypothetical examples of different input sequences that a subject might receive during the step-down condition (left panels). For Session 1 (top panel), the input series consists of $1015-\mathrm{sec}$ IFIs followed by $405-\mathrm{sec}$ IFIs. For Session 2, there are 4015 -sec IFIs followed by 105 -sec IFIs. In another session (Session $\mathrm{n}$, bottom panel), the series contains 25 15-sec IFIs followed by 255 -sec IFIs.

\section{RESULTS}

Across sessions, the number of IFIs preceding and following a transition varied because the location of a transition varied. Therefore, we used the following averaging method to determine the effect of a transition on waittime duration, measured as the time between a reinforcer 

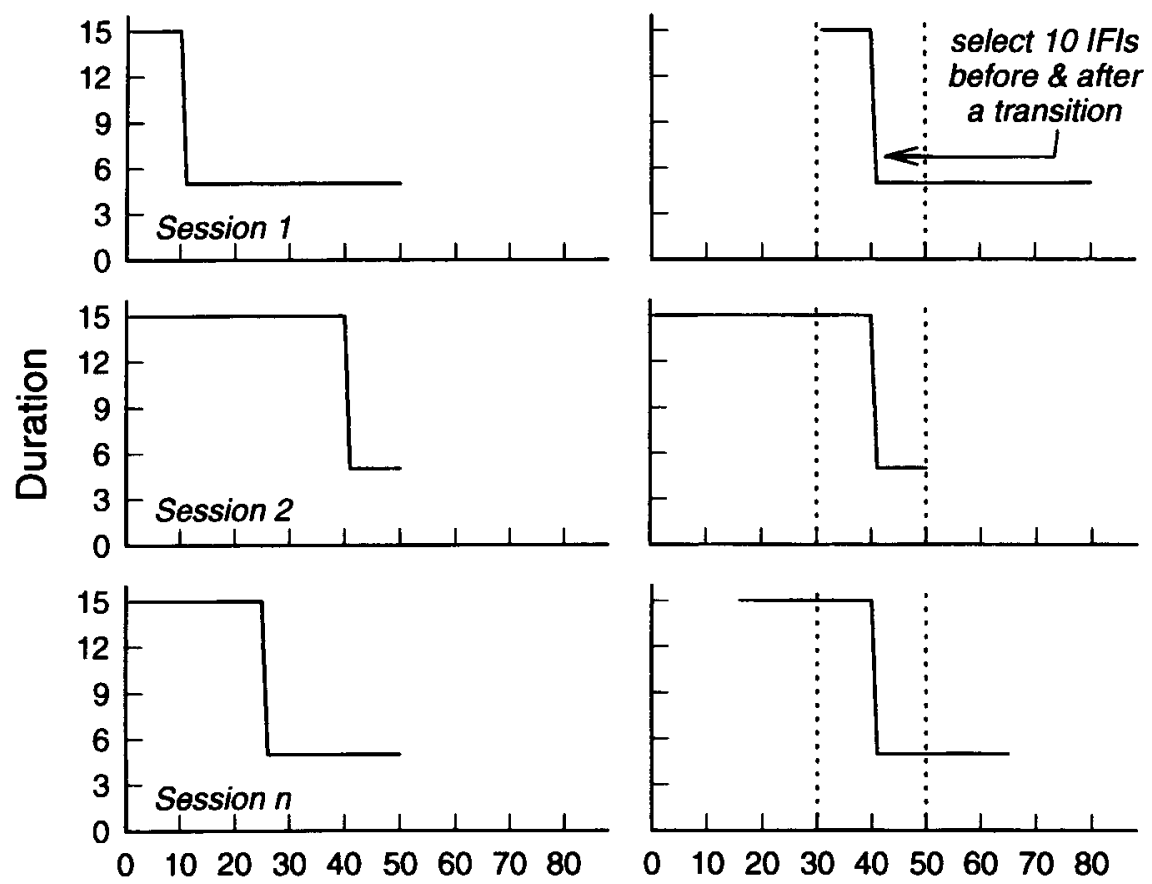

\title{
Interfood Interval Number
}

\begin{abstract}
Figure 1. The left set of panels illustrates hypothetical input series a subject might receive during the step-down condition. The right set of panels depicts the averaging method used, which is based on the input series depicted in the left. For each session, the 10 interfood intervals (IFIs) preceding and following a transition (marked with dashed vertical lines) were extracted, and the average wait time in these IFIs was calculated.
\end{abstract}

and the first leverpress within an IFI. For each session, we extracted the wait time from the 10 IFIs preceding and following a transition and then calculated the average wait time in each of these IFIs. Figure 1 (right panel) illustrates the averaging method using the input series in the left panel. For the no-step condition, the computer program chose an arbitrary transition IFI for each session, between the 10th and 41 st IFIs. In all statistical tests that follow, the significance level was set at $p \leq .05$.

Figure 2 presents the results from Phase 1 of the experiment. It shows data from individual subjects and the group average. One graph (top) presents the results from both no-step conditions. The unfilled symbols and heaviest line represent data from the first no-step condition, whereas the filled symbols and thinner line mark data from the second no-step condition. Figure 3 presents the results from Phase 2.

To begin, overall wait time either decreased slightly from the first to second no-step condition (Phase 1) or increased (Phase 2). This finding at the group level was not consistent across subjects, however, and was not systematic with respect to the sequence of conditions each animal experienced. In addition, wait time did not systematically change before and after an arbitrarily chosen transition point for all but one of the no-step conditions. A two-way repeated measures analysis of variance (ANOVA) was not significant for the first $[F(1,3)=0.28]$ and second $[F(1,3)=1.88]$ no-step conditions of Phase 1 and was not significant for the second no-step condition of Phase $2[F(1,3)=3.35]$. However, wait times significantly increased across IFIs during the first no-step condition of Phase $2[F(1,3)=29.50]$.

In Phase 1, a step-down and a step-up transition caused an overall decrease and increase in wait times, respectively. For the step-down condition, the average wait time decreased by approximately $38 \%$ from a pretransition level of $5.38 \mathrm{sec}$ to a posttransition level of $3.35 \mathrm{sec}$. For the step-up condition, average wait time increased by $152 \%$ above a pretransition level of $7.38 \mathrm{sec}$ to a posttransition level of $18.63 \mathrm{sec}$. Both effects were statistically significant [step-down, $F(1,3)=16.745$; step-up, $F(1,3)=64.99]$. In Phase 2 of the experiment, wait times significantly decreased by $64 \%$ during step-down from 31.29 to $11.37 \mathrm{sec}[F(1,3)=34.565]$ and significantly increased by $74 \%$ from 42.13 to 73.23 sec during stepup $[F(1,3)=52.205]$.

How fast did the rats' wait times adjust to a transition? In all conditions and phases, a transition had an immediate effect on wait time. A decrease in IFI duration caused wait time to decrease in the next IFI. Similarly, an increase in IFI duration caused wait time in the next IFI to increase above pretransition levels. (Recall that the occurrence of a transition was unpredictable; therefore, wait time in the first transition IFI should be approximately the same as that during pretransition IFIs.) However, adjustment of wait times beyond the first two posttransition intervals 

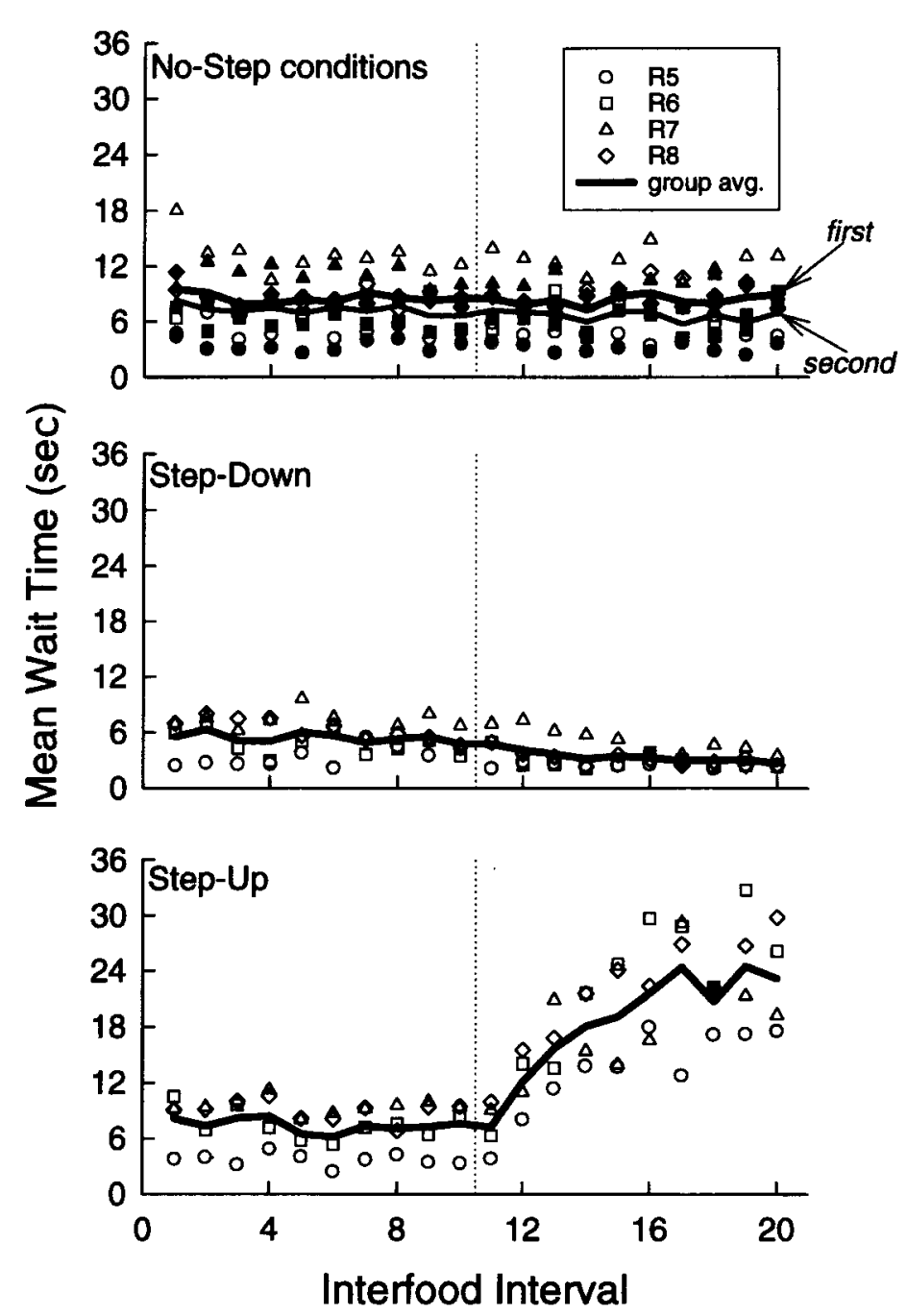

\begin{abstract}
Figure 2. Mean wait time for individual subjects (symbols) and the group average (lines) during baseline and experimental conditions from Phase 1. Wait times are from the 10 interfood intervals (IFIs) preceding and following a step-down and a step-up transition (dashed vertical line) in IFI duration. For no-step conditions, the computer program chose an arbitrary transition point. Data from the first no-step condition are shown as unfilled symbols (the group average as a heavy line), and those from the second condition are shown as filled symbols (the group average as a thinner line).
\end{abstract}

differed in the step-down and step-up conditions. Adjustment was complete after the third or fourth posttransition interval during step-down. This is clearest in Figure 3 and more difficult to see in Figure 2 because of the $y$-axis scale. In contrast, adjustment of wait time to a stepup transition in IFI duration was not complete until the seventh posttransition IFI in Phase 1 (Figure 2) and the fifth posttransition in Phase 2 (Figure 3).

Figure 4 shows how wait times changed following the decrease and increase in IFIs during the step-down and step-up conditions, respectively. To study the effects of training, we used the results from the posttransition IFIs shown in Figures 2 and 3 and calculated average wait time during Sessions 1-7 and Sessions 8-14. The figure also shows standard errors for these data and average wait time in pretransition IFIs for comparison. Two main re- sults are evident. First, the transition patterns in Figures 2 and 3 were present during the first few sessions of exposure. Second, wait times tended to decrease with training during step-down and lengthen during the step-up condition of Phase 2.

\section{DISCUSSION}

The results from this experiment revealed dynamic properties of rats' responses to a within-session shift in IFI duration. The rats responded to an abrupt decrease (or increase) in IFI duration by shortening (or lengthening) their wait time in the next interval. Because the transition point varied across sessions, it is unlikely that factors other than the preceding IFI duration (such as the time since the start of a session) controlled wait-time du- 

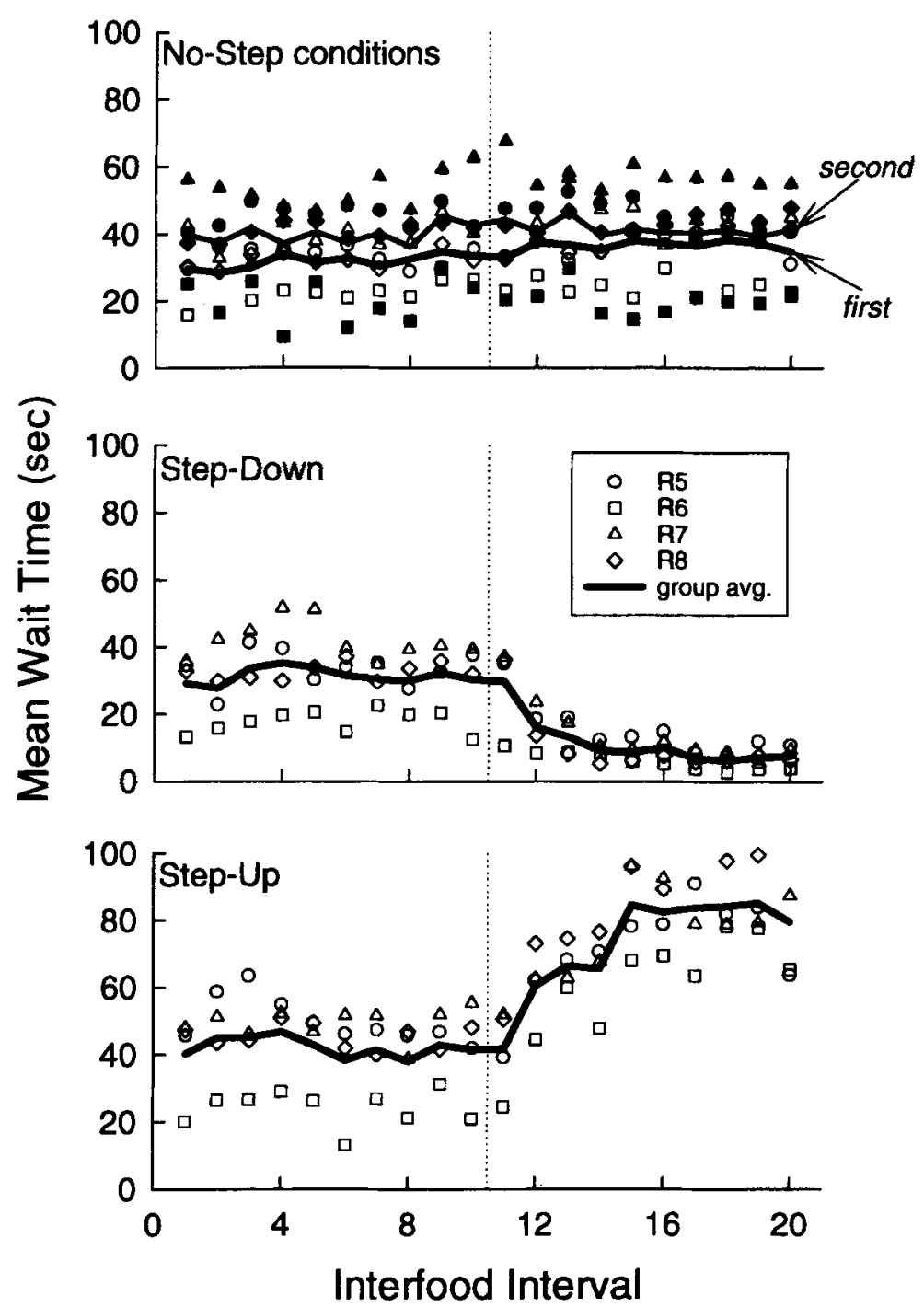

Figure 3. Mean wait time for individual subjects (symbols) and the group average (lines) during baseline and experimental conditions from Phase 2. Wait times are from the 10 interfood intervals (IFIs) preceding and following a step-down and a step-up transition (dashed vertical line) in IFI duration. For no-step conditions, an arbitrary transition point was chosen. Data from the first no-step condition are shown as unfilled symbols (the group average as a heavy line), and those from the second condition are shown as filled symbols (the group average as a thinner line).

ration. On the other hand, although the transition point was unpredictable, the rats may have learned that the first interval after a transition signaled a period in which IFIs remained shorter or longer throughout a session. There is some evidence of this effect in Figure 4, which shows that wait times decreased overall with training during step-down and increased during the step-up condition in Phase 2.

Next, the adjustment of wait times in subsequent IFIs depended on the direction in which the IFIs changed. Wait times adapted quickly (within a few intervals) during step-down and more gradually during step-up. It is important to note that wait times increased significantly from pre- to posttransition intervals during the first no- step condition of Phase 2. Thus, it is possible that responding in the next experimental condition (step-down for some rats, step-up for others) was confounded by the tendency of wait times to increase across a constant series of IFIs. However, wait times did not significantly change in the other no-step conditions. What may explain the increase in wait times in the no-step condition of Phase 2 is that this was the first exposure for all subjects to a fourfold increase in IFI duration. Consequently, there may have been an ongoing adjustment of wait times to the much longer IFIs. In spite of this increasing trend, the decrease in wait time during a step-down transition was significant. Moreover, wait time significantly increased above pretransition levels during step-up. 


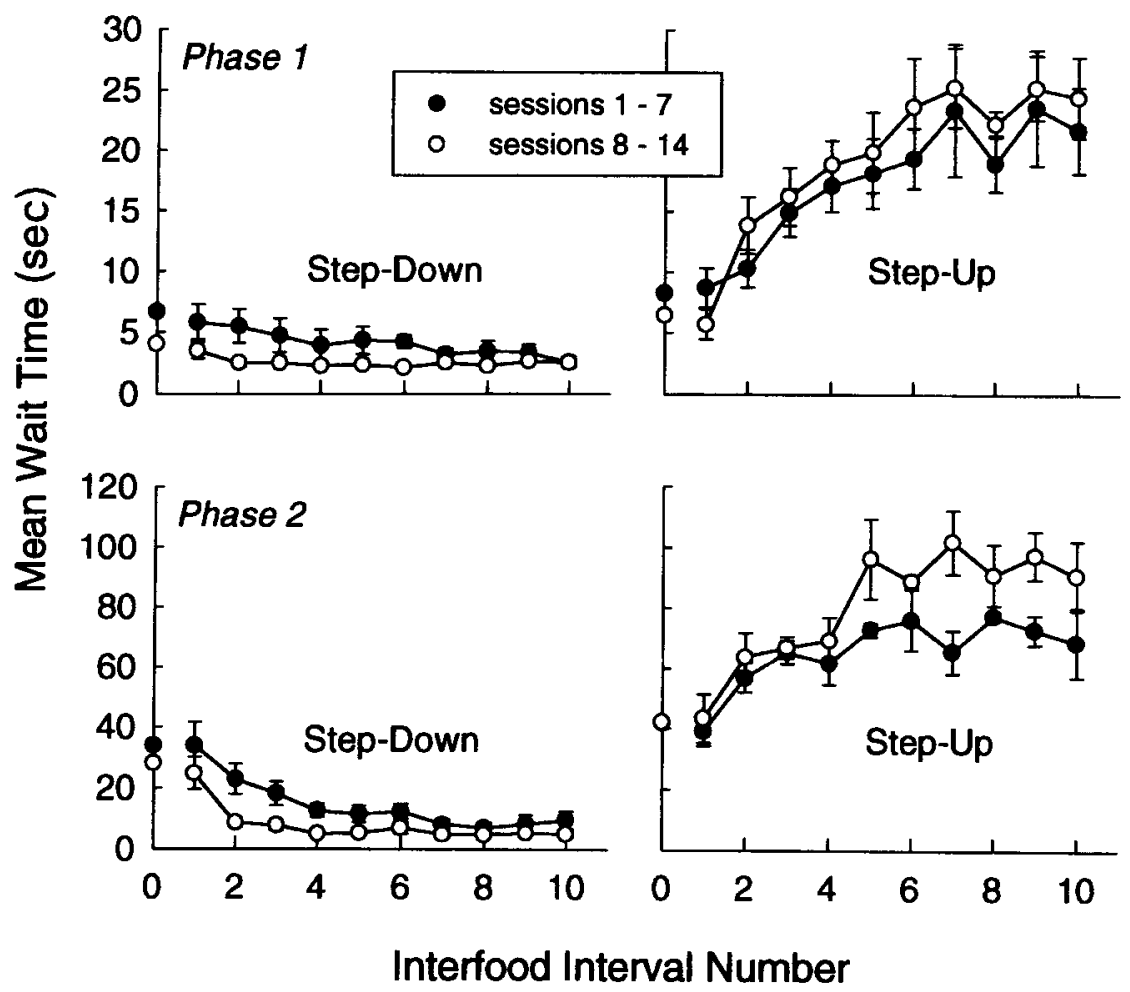

Figure 4. Average posttransition wait times during the first (filled circles) and last (unfilled circles) seven sessions of training. The symbols located on the $y$-axis indicate mean wait times during pretransition intervals. Note that, for the step-up condition in Phase 2, the average pretransition wait time is similar for Sessions 1-7 (42.0 sec) and Sessions 8-14 (42.26 sec).

Our main results with rats are consistent with studies using pigeons as subjects under comparable conditions (Higa et al., 1993). One noticeable difference, however, is that pigeons showed larger overall decreases in wait times than did rats when IFIs changed from 15 to $5 \mathrm{sec}$. It is unlikely that the difference depends on the way in which IFI duration is programmed (the present experiments used FI schedules, whereas other studies typically use RID schedules) because time discrimination-measured as wait-time responses - is controlled by the time between two reinforcers (Innis, Cooper, \& Mitchell, 1993). In addition, wait time does not appear to depend on factors that often change response rate in an interval, such as changing the color on a key after the first peck (e.g., Shull, 1970). A floor effect is likely behind the smaller change in wait-time duration in rats. For instance, when we increased the duration of IFIs by a factor of four (while holding constant the proportion by which IFIs changed), we observed a larger percentage change in IFIs during step-down, but the overall pattern of wait times appeared unaffected. Therefore, the general properties of temporal dynamics do not appear to depend on the absolute duration of the IFIs used.

Rapid changes in wait time appear similar to recent results from studies on choice. For instance, rats rapidly track wide and unsignaled fluctuations in relative rates of reinforcement (brain stimulation): Adjustment of time spent responding on two levers is complete within one or two interreinforcer intervals on the lever associated with the leaner schedule (Mark \& Gallistel, 1994). It is too early to determine the relation between these kinds of results and results from the present experiment. Nonetheless, there are interesting differences that should be addressed in future experiments. For one, Mark and Gallistel (1993) reported that the rate of adjustment to a change in relative reinforcement rate depends on the amount of exposure to a prolonged period of stability before the change. Rats appear to adjust slowly after a long stability period and adjust rapidly if they have experienced several changes in their recent past. The data from experiments on temporal control indicate a different effect of training. For example, when IFIs changed frequently (according to a repeating cycle of $15,5,15$, $45 \mathrm{sec}$ ), pigeons initially tracked the sequence by basing wait time on the preceding IFI duration. However, tracking eventually disappeared and was replaced by a variable-interval-like performance - that is, a postfood wait time appropriate to the shortest IFI duration (Higa et al., 1993).

The present results also have important implications for theories of time discrimination. Most models (e.g., SET and BeT) are based on molar features of the experimental condition or a theoretical pacemaker process and are designed to explain steady-state properties of timing. 
These models are quasi-dynamic (Staddon, 1988) and do not specify how timing is affected by individual intervals presented during training. Hence, they cannot readily explain the effects from a single interval or recent changes in IFI duration. Models aimed at dynamics have been somewhat more successful.

Wynne and Staddon (1988) proposed a linear waiting model for timing dynamics. According to linear waiting, wait time in one interval $\left(\mathrm{IFI}_{n}\right)$ is driven by the justpreceding interval duration ( $\mathrm{IFI}_{n-1}$ ). A study by Higa et al. (1991) provided evidence in support of linear waiting. Using pigeons as subjects, they intercalated an occasional 5-sec IFI into a long sequence of 15 -sec IFIs and looked to see whether wait times decreased following the 5-sec IFI, as predicted by a linear waiting process. They discovered that the 5 -sec IFI decreased wait time in the immediately following IFI and that the decrement was localized. In other words, after an initial decrease, wait times in subsequent IFIs returned to levels observed in the IFIs preceding the change.

However, although linear waiting fits a considerable range of dynamic data (e.g., see Wynne \& Staddon, 1988, 1992), the results from the present experiment indicate that it is an incomplete explanation. Under some conditions, wait times beyond the first IFI of a transition systematically changed. During a step-down or step-up transition, wait time in the next IFI decreased or increased, respectively, as predicted by linear waiting, but wait times beyond the first few transition IFIs continued to change in the step-up condition. The latter result is inconsistent with a strict linear waiting model, which predicts a distinct stepwise pattern of change in wait time under both conditions.

To conclude, the results from this study and others (Higa, 1996; Higa et al., 1993) suggest a timing process that is sensitive to both recent and remote changes in individual IFIs that an animal experiences. A challenge for future theoretical work is to incorporate these factors. A model based on a weighted moving average of prior IFIs (e.g., Wynne et al., 1996) or one in which wait time is determined by the frequency and recency of preceding IFIs (e.g., Higa, 1996; Staddon \& Higa, 1991) offer other possibilities about how timing depends on the interaction among individual IFIs. Further research on temporal dynamics should help to evaluate these models and unravel the underlying processes of temporal control.

\section{REFERENCES}

Brunner, D., Kacelnik, A., \& GibBon, J. (1992). Optimal foraging and timing processes in the starling, Sturnus vulgaris: Effect of inter-capture interval. Animal Behavior, 44, 597-613.

CATANiA, A. C. (1970). Reinforcement schedules and psychophysical judgments: A study of some temporal properties of behavior. In W. N. Schoenfeld (Ed.), The theory of reinforcement schedules (pp. 1-42). New York: Appleton-Century-Crofts.

CHENG, K., \& Westwood, R. (1993). Analysis of single trials in pigeons' timing performance. Journal of Experimental Psychology: Animal Behavior Processes, 19, 56-67.
Church, R. M. (1984). Properties of the internal clock. In J. Gibbon \& L. Allan (Eds.), Timing and time perception (Annals of the New York Academy of Sciences, Vol. 423, pp. 566-582). New York: New York Academy of Sciences.

Fetterman, J. G., \& Killeen, P. R. (1991). Adjusting the pacemaker. Learning \& Motivation, 22, 226-252.

GibBon, J. (1977). Scalar expectancy and Weber's law in animal timing. Psychological Review, 84, 279-325.

GiBBON, J. (1991). Origins of scalar timing. Learning \& Motivation, 22, 3-38.

GibBon, J. (1995). Dynamics of time matching: Arousal makes better seem worse. Psychonomic Bulletin \& Review, 2, 208-215.

GibBON, J., \& Balsam, P. (1981). Spreading association in time. In C. M. Locurto, H. S. Terrace, \& J. Gibbon (Eds.), Autoshaping and conditioning theory (pp. 219-251). San Diego: Academic Press.

GibBON, J., \& CHURCH, R. M. (1984). Sources of variance in an information processing theory of timing. In H. L. Roitblat, T. G. Bever, \& H. S. Terrace (Eds.), Animal cognition (pp. 465-488). Hillsdale, $\mathrm{NJ}$ : Erlbaum.

Harzem, P., Lowe, C. F., \& Davey, G. C. L. (1975). Two-component schedules of differential-reinforcement-of-low-rate. Journal of the Experimental Analysis of Behavior, 24, 33-42.

HIGA, J. J. (1996). Dynamics of time discrimination: II. The effects of multiple impulses. Journal of the Experimental Analysis of Behavior, 66, 117-134.

Higa, J. J., Thaw, J. M., \& Staddon, J. E. R. (1993). Pigeons' waittime responses to transitions in interfood interval duration: Another look at cyclic schedule performance. Journal of the Experimental Analysis of Behavior, 59, 529-541.

Higa, J. J., WynNe, C. D. L., \& Staddon, J. E. R. (1991). Dynamics of time discrimination. Journal of Experimental Psychology: Animal Behavior Processes, 17, 281-291.

INNIS, N. K. (1981). Reinforcement as input: Temporal tracking on cyclic interval schedules. In M. L. Commons \& J. A. Nevin (Eds.), Quantitative analysis of behavior: Discriminative properties of reinforcement schedules (pp. 257-286). New York: Pergamon.

InNis, N. K., COOPer, S. J., \& Mitchell, S. K. (1993). The determinants of postreinforcement pausing. Behavioural Processes, 29, 229 238.

KilleEn, P. R., \& Fetterman, J. G. (1988). A behavioral theory of timing. Psychological Review, 95, 274- 295.

LEJEUNE, H., \& WEARDEN, J. H. (1991). The comparative psychology of fixed-interval responding: Some quantitative analyses. Learning \& Motivation, 22, 84-111.

Lowe, C, F., \& HARzEM, P. (1977). Species differences in temporal control of behavior. Journal of the Experimental Analysis of Behavior, 28, 189-201.

Mark, T. A., \& Gallistel, C. R. (1993, November). The microstructure of matching. Paper presented at the 34th Annual Meeting of the Psychonomic Society, Washington, DC.

MARK, T. A., \& GALLISTEL, C. R. (1994). Kinetics of matching. Journal of Experimental Psychology: Animal Behavior Processes, 20, 79-95.

MECK, W. H., \& ChurCh, R. M. (1984). Simultaneous temporal processing. Journal of Experimental Psychology: Animal Behavior Processes, 10, 1-29.

Richelle, M., \& Lejeune, H. (1980). Time in animal behavior. Oxford, U.K.: Pergamon.

ROBERTS, S. (1981). Isolation of an internal clock. Journal of Experimental Psychology: Animal Behavior Processes, 7, 242-268.

SCHNEIDER, B. A. (1969). A two-state analysis of fixed-interval responding in the pigeon. Journal of the Experimental Analysis of Behavior, 12, 667-687.

SHuLL, R. L. (1970). The response-reinforcement dependency in fixed-interval schedules of reinforcement. Journal of the Experimental Analysis of Behavior, 14, 55-60.

STADDON, J. E. R. (1965). Some properties of spaced responding in pigeons. Journal of the Experimental Analysis of Behavior, 8, 19-27.

STAdDon, J. E. R. (1988). Quasi-dynamic choice models: Melioration and ratio invariance. Journal of the Experimental Analysis of Behavior, 49, 303-319. 
Staddon, J. E. R., \& Higa, J. J. (1991). Temporal learning. In G. H. Bower (Ed.), The psychology of learning and motivation (Vol. 27, pp. 265-294). San Diego: Academic Press.

WynNe, C. D. L., \& StADDON, J. E. R. (1988). Typical delay determines waiting time on periodic-food schedules: Static and dynamic tests. Journal of the Experimental Analysis of Behavior, 50, 197-210.

WYNNE, C. D. L., \& STADDON, J. E. R. (1992). Waiting in pigeons: The effects of daily intercalation on temporal discrimination. Journal of the Experimental Analysis of Behavior, 58, 47-66.
Wynne, C. D. L., Staddon, J. E. R., \& Delius, J. D. (1996). Dynamics of waiting in pigeons. Journal of the Experimental Analysis of Behavior, 65, 603-618.

ZEILER, M. D., \& Powell, D. G. (1994). Temporal control in fixed-interval schedules. Journal of the Experimental Analysis of Behavior, 61, 1-9.

(Manuscript received October 19, 1995; revision accepted for publication August 16, 1996.) 